\title{
THE CHALCIDOID PARASITES OF THE COMMON HOUSE OR TYPHOID FLY (MUSCA DOMESTICA LINN.) AND ITS ALLIES. ${ }^{1}$
}

\author{
By A. A. Girault and George Ethelbert Sanders. \\ The University of Illinois. \\ Habits in General and Biology.
}

A. Oviposition. This appears to be the only function of the female. When thus engaged she is not easily disturbed and the function is normally performed even in small capsules or vials, and in the insectary at various times, females were often observed attempting to gain entrance to breeding-cages containing their hosts; in the case of large cages they were quite often successful and under certain conditions it was impossible to keep them out. The following detailed, though fragmentary observations were made on ovipositing females.

(1) Sept. 12, 1908.- The female often faces towards the caudal end of the host puparium when engaged in ovipositing - on this date, in the cases of 8 host puparia (Phormia regina), apparent oviposition was observed once in four cases and twice in the other four - the times of these ovipositions were between 9:55 A. M. and 1:20 P. M. and the time required to deposit a single egg varied from $1 \frac{1}{2}$ minutes to 16 , averaging $7 \frac{1}{2}$ minutes; the particular spot on the host puparium into which the ovipositor of the female was inserted was usually in the region of the 4th and 5th segments, but varied to the 6th and 7th or 7th and 8th. The hole made by the ovipositor was not distinct afterwards, but in many cases it became covered with a white mycelium-like growth the nature of which we have not determined. (2) On Sept. 29, 1908, at 11:30 A. M., in the case of three virgin females ovipositing into the puparia of Phormia regina, the ovipositor was inserted for its full length for 3, 7 and 8 minutes respectively. (3) On Sept. 13, 1908 , a female was watched while ovipositing into a hard puparium of the Phormia. The puparium was pierced by rotating the ovipositor and pressing it down, the force of the pressure often causing the organ to bend, when the rotary motion was more easily seen; this continued 
for 11 minutes; the abdomen, during this time, was inclined upward, its tip applied to the surface and the ovipositor appearing as a perpendicular rod issuing from the venter slightly beyond the proximal third. After drilling through the crust of the puparium, the rotary motion was considerably lessened but not entirely discontinued and 10 more minutes were consumed in working the ovipositor back and forth, apparently in order to enlarge the aperture, the edges of which were frayed. The ovipositor was then pushed farther into the aperture, the abdomen moving up and down slightly and gradually being triangularly or conically produced at the base of the ovipositor, and as the latter entered farther, approaching nearer and nearer to the surface of the puparium, until after 30 seconds the ovipositor was fully inserted. The female then remained motionless for $3 \frac{5}{6}$ minutes, when the ovipositor was partially redrawn and reinserted two or three times, and finally wholly withdrawn from the host, assuming its usual concealed position within the valves along the venter. Upon the withdrawal of the ovipositor, the female immediately left the host. The time that she was engaged in the whole operation was $25 \frac{1}{3}$ minutes. (4) Observations made on three females depositing eggs into puparia of the Phormia, on Sept. 29, 1908, showed in three instances that the ovipositor was fully inserted for 70,90 and 95 seconds respectively. (5) On Sept. 18, 1908, a female of this parasite was confined in a small homeopathic vial with a quantity of muscid puparia of varying ages - some three or four days old, some but several hours. The female chose an "old" puparium, formed about two days, and apparently deposited three eggs into it, one following the other. At first, she chose a place for inserting the ovipositor by examining closely the entire surface of the host; the ovipositor was then guided to the spot by bending the abdomen, the whole body convexly bent, the head turned as though the insect was watching the operation; as soon as placed, the ovipositor was released from the valves along the venter and the abdomen assumed its usual position. Piercing the shell of the puparium required $1 \frac{1}{2}$ minutes; the ovipositor was then inserted for its entire length, without other delay, and as quickly withdrawn, fiftv seconds being occupied in enlarging the hole. After this short period of time, the ovipositor was pushed in again for its entire length, remaining so for forty-five seconds, during which time, apparently, the egg was deposited. After the ovipositor was withdrawn, the parent parasite carefully examined the puncture with the antennae 
and mandibles and apparently also by means of sight. (6) The deposition of an egg observed at 9:45 P. M., Sept. 14, required 16 minutes; the host was Phormia regina. Another observation made at 10:15 A. M. the same day, showed that the act required 8 minutes; the host puparium was that of Musca domestica; in the latter case, the ovipositor was inserted into the 9th segment of the host. A female was observed to deposit an egg in confinement at 7:30 A. M. to-day. (7) A female confined at 9:20 A. M., Sept. 10, deposited into puparia of the Phormia at 9:32 A. M. and 1:20 P. M. the same day. One confined at $10 \mathrm{~A}$. M. the same date with 2 puparia of the same host oviposited at once. (8.) In the cases of 4 females confined separately in vials each with 4 (in one case 8 ) puparia of Cynomyia cadaverina Desv., April 29, 1909, oviposition occurred with one female at 10:25 P. M., April 30, and again at 9 P. M., May 1; no other observations were recorded. (9.) Nine males and twenty females confined at 11:20 A. M., April 29, with 10 puparia of the same host commenced oviposition about noon, or sooner, and oviposition was observed at nearly every hour between 9 A. M. and 11 P. M., for several days.

B. Nature of the Parasitism. Examinations made of parasitized hosts, showed that in all cases, the parasite is "social" or gregarious and does not attack the host until after the formation of the puparium, preferably after the latter has been formed for at least twenty-four hours. Puparia of Phormia regina examined, were in some cases filled entirely with the larvae of the parasite which had totally consumed the host pupa; for example, from one puparium 47 larvae of the parasite were removed; from another 8 larval parasites were removed, together with a shriveled pupa of the host - none of the parasitic grubs had entered the body of the latter, which indicates that the parasites are external as far as the host pupa is concerned, obtaining their nourishment by means of absorption; in the case just cited, one of the parasitic larvae was attached to the head of the host pupa over the eye, one to the thorax and six to the abdomen. In a third Phormia puparium, there were found 21 larval parasites, the host pupa being totally consumed; in four more single cases there were 8, 13, 13 and 16 larvae of the parasite respectively. In another, 27 parasitic pupae were found, from a single puparium of Sarcophaga sp. "e" 22 Ђ the parasite were taken. As a rule, the remains of a parasitized host - the fully formed pupa - is a flat, scale-like mass apparently consisting of the ventral shell of the pupa and that of the head; for 
example, the thecae of the eyes, legs and wings are discernible, and the remains are not much shrunken, so far as the original length is concerned. In the case of Cynomyia cadaverina, in one puparium infested with 21 larvae of the first spring generation, the parasites were all attached to the dorsal surface of the host from the pronotum to the tip of the abdomen; these parasitic larvae were nearly full-grown. But in another puparium of the same host, in which 13 larvae were found, their attachment to the host appeared to be haphazard, and the host pupa was considerably shrunken, especially in width. It is evident, from their appearance, and from the fact that the larger larvae are found attached externally to the host - between it and the inner walls of the puparium - that the larval parasites obtain their nourishment through the body wall of the host pupa, leaving the integument intact. In both of the latter cases, the host pupae were nearing the final ecdysis when they were attacked by the parasites.

Although gregarious, the host is not as completely destroyed as by Spalangia, Muscidifurax or Pachycrepoideus, which though solitary parasites, reduce the host to a mere flat unrecognizable shell.

In addition to the foregoing, Mr. Maurice C. Tanquary has kindly collated the following records from our rearing notes:

Table I. Number and sex of parasites (Nasonia brevicornis) ISSUING FROM PUPARIA OF Phormia regina.

\begin{tabular}{|c|c|c|c|c|c|c|}
\hline Males & Females Larvae. & Total. & Males. & Females. & Larvae. & Total. \\
\hline 8 & 7 & 15 & 0 & 5 & & 5 \\
\hline 3 & 6 & 9 & 0 & 1 & & 1 \\
\hline 10 & 4 & 14 & 5 & 0 & & 5 \\
\hline 5 & 3 & 8 & 9 & 6 & & 15 \\
\hline 1 & 13 & 14 & 1 & 6 & & 7 \\
\hline 9 & 5 & 14 & 6 & 16 & & 22 \\
\hline 10 & 17 & 27 & 0 & 5 & & 5 \\
\hline 7 & 6 & 13 & 16 & 5 & & 21 \\
\hline 13 & 11 & 24 & 0 & 7 & & 7 \\
\hline 4 & 9 & 13 & 2 & 12 & & 14 \\
\hline 6 & 15 & 21 & 1 & 4 & & 5 \\
\hline 0 & 17 & 17 & 3 & 9 & & 12 \\
\hline 15 & 5 & 20 & 3 & 8 & & 11 \\
\hline 1 & 21 & 22 & 7 & 12 & & 19 \\
\hline 10 & 4 & 14 & 6 & 4 & & 10 \\
\hline 4 & 6 & 10 & 1 & 10 & & 11 \\
\hline 6 & 7 & 13 & 3 & 9 & & 12 \\
\hline
\end{tabular}


Males. Females. Larvae. Total. 5

$7 \quad 1$

$1 \quad 10$

$17 \quad 0$

$2 \quad 7$

$4 \quad 11$

$4 \quad 10$

$1 \quad 6$

$\begin{array}{ll}3 & 7\end{array}$

$2 \quad 11$

23

$5 \quad 11$

110

19

$17 \quad 5$

$38 \quad 4$

$6 \quad 10$

$\begin{array}{ll}1 & 2\end{array}$

$1 \quad 2$

$\begin{array}{ll}4 & 7\end{array}$

154

60

$5 \quad 1$

$5 \quad 5$

110

$5 \quad 14$

$0 \quad 4$

$9 \quad 11$

65

$2 \quad 1$

$15 \quad 12$

$8 \quad 8$

$\begin{array}{ll}1 & 7\end{array}$

$2 \quad 1$

$7 \quad 9$

$8 \quad 12$

$9 \quad 3$

$0 \quad 6$

$7 \quad 9$

$12 \quad 7$

$4 \quad 12$

$0 \quad 3$

$9 \quad 13$

$7 \quad 11$

$\begin{array}{ll}1 & 9\end{array}$

$\begin{array}{ll}3 & 8\end{array}$

8

11

17

9

15

14

7

10

13

5

16

11

10

22

42

16

3

3

11

19

6

6

10

11

19

4

20

11

3
27
16

16

8

3

16

18

12

6

16

19

16

3

22

18

10

14
Males. Females. Larvae. Total. $\begin{array}{lll}9 & 13 & 22\end{array}$
10

19

12

19

$10 \quad 9$

9

4

19

15

29

114

6

9

8

4

4

6

21

7

17

15

6

11

10

28

5

11

15

12

13

2

34

6

9

12

15

12

8

3

10

8

6

6

4

6

23 
The puparia from which the foregoing records were made were selected at random from a large quantity formed by maggots obtained August 28, 1908, in the decomposed cadaver of a large angora cat, taken from the city dumping-grounds, Champaign, Illinois. Each puparium was confined separately in a gelatine capsule, until the parasites emerged; they were confined on Sept. 15, and on Sept. 29 the majority of the parasites had emerged; the count was not made, however, until nearly a month later, or on Oct. 19, 1908.

In 119 puparia there were 1496 individuals of Nasonia brevicornis, of which 710 were males and 786 females. The average number of males in each puparium was 5.96, of females 6.60 ; the average number of specimens from each puparium was 12.57. Of the whole number, $52.4 \%$ were females and $47.6 \%$ males. The averages do not include 8 larvae found in two of the hosts.

On the date of counting - October 19 th -8 of the puparia were found to contain larvae of the parasite, some in addition to the adults, over half of the larvae being still alive; but 14 of the puparia contained only dead pupae of the host, that is to say, were not parasitized. So that of the 140 puparia examined, 14 were not parasitized, 126 were. The total number of parasites in the 126 parasitized puparia, including larvae, was 1555, and on this basis, the average for each host was 12.34, very near the former average. The maximum number of parasites obtained from a single host (Phormia regina) was 47, recorded in the first paragraph of this section; the minimum was 1 , recorded in the table.

The meconial discharges of this parasite, found scattered through the host puparium, are brownish yellow or dark olive green in color and consist of small conglomerations of round pellets, or are sometimes in irregular chains like some bacteria, but are never single, solid pieces as with Pachycrepoideus, Spalangia and Muscidifurax.

C. Length of the Period of Oviposition. In the cases of two females captured and confined together with eight puparia of Musca domestica at 11:30 A. M., Sept. 10, the first oviposition was observed at 1 P. M., Sept. 10, the second at 7:30 A. M., the following day, the third at 10 A. M., Sept. 14, and the fourth and last, fifteen minutes later; here, at least, oviposition was continued over a period of $3 \frac{1}{2}$ days or more.

In the case of 9 males and 20 females, parents of the first spring generation of 1909, which were confined at 11:20 A. M., April 29, 1909, with 10 healthy puparia of Cynomyia cadaverina which were 
freshly emerged (average, 9 A. M., April 29) and of the same age, oviposition was begun at noon the same day and continued steadily until at least 9 P. M., May 2, 1909, when further observations were interrupted. These facts also hold for a single female of the same lot confined separately with 8 of the hosts.

D. Time Elapsing between Emergence and Reproduction. Eleven adults of mixed sexes emerging from a single puparium of Phormia regina, from 11:45 A. M. to noon, Sept. 28, 1908, were at once confined together with four healthy puparia of the same host. At noon the following day oviposition was observed, or after a period of twentyfour hours. One pair of adults emerging at 8 A. M., Sept. 30, was confined immediately with seven healthy puparia of the same host; at 8:13 A. M. mating was observed and at 6:50 P. M. the same day the female was observed ovipositing; or after $10 \frac{1}{2}$ hours. Mating in this instance followed almost immediately after emergence, and lasted for 14 seconds. In the case of the parents of the first spring generation of 1909, mating followed almost immediately after emergence and oviposition about 3 hours later.

E. Duration of the Pupal Stage. This was obtained in one case only. A larva pupated during the night of Sept. 17-18, 1908, the newly formed pupa being yellowish white; by the twenty-first of the same month, the pupa had assumed nearly the colors of the adult, dark greenish, the head and thorax coloring first, the abdomen a few hours later. The resulting adult female emerged at $10 \mathrm{~A}$. M., Sept. 23, 1908, making a pupal stage of approximately $5 \frac{1}{2}$ days. The average length of this stage for the first spring generation (17 cases) was 9 days (May 14-23, 1909).

F. Length of the Life Cycle. The few incidental observations obtained on this point are herewith given in tabular form. (Table II, p. 16.)

Thus while the average daily effective temperature shows a gradual decrease, there seems to be no corresponding increase in the duration of the cycle.

The duration of the cycle appeared to be somewhat longer in the case of the first spring generation, however, when the daily average effective temperature was low. Thus, hosts exposed to recently mated adults from noon, April 29, 1909, to late on May 2 - oviposition continuing throughout that time - were filled with the nearly full-grown larvae of the parasite on May 13, pupation com- 
Table II. Duration of the Lile Cycle in Nasonia brevicornis, 1908.

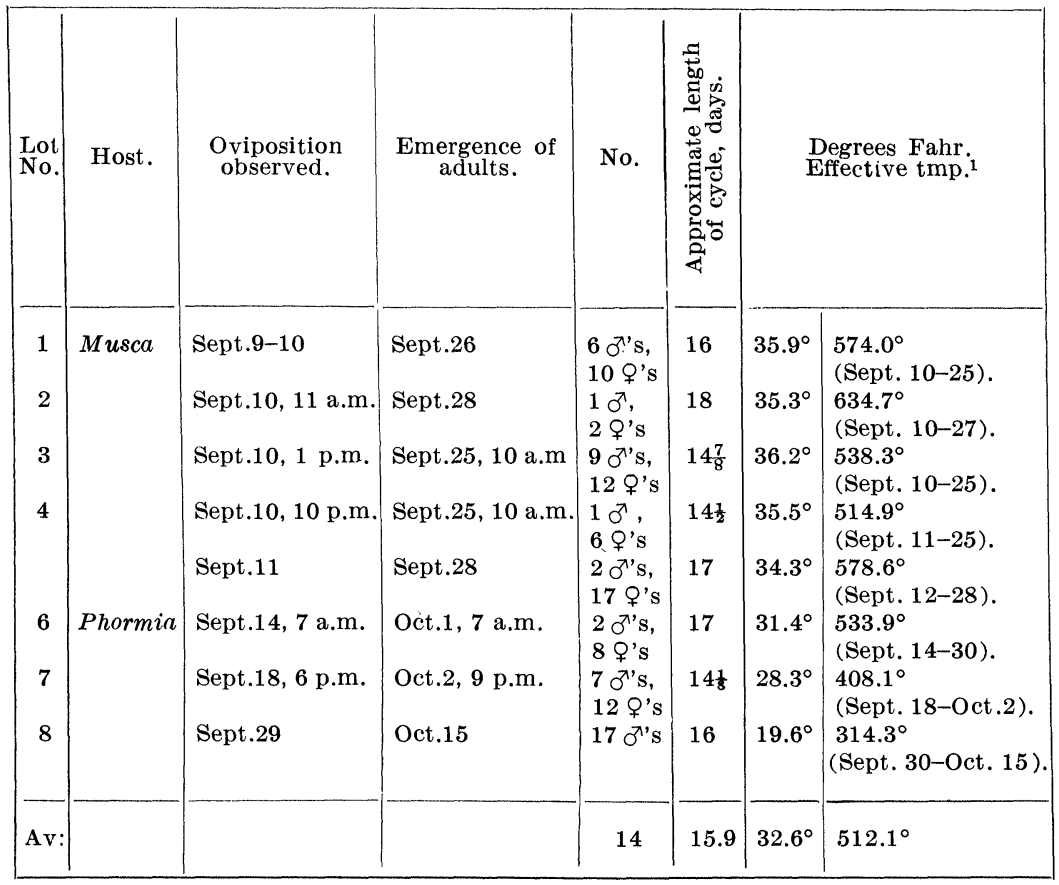

mencing on May 14 at the average time of 4 P. M. Emergence of the adults occurred at 4 P. M., May 22, becoming general at 3 P. M., May 24. Hence, taking average time, the life cycle in this case had an average duration of $22 \frac{1}{2}$ days, natural temperatures.

G. Progeny of a Single Female. The number of observations which we were able to make concerning the fecundity of the species was not large, but those which are tabulated in the attached table (table III) appear to show that there is quite a wide range, within certain limits, which is more or less dependent upon the number of host puparia available for purposes of oviposition and also the host species. For instance, it is at once noticed that the most productive females had access to a comparatively large number of the host

${ }^{1}$ Inception of development taken as $43^{\circ} \mathrm{Fahr}$. Sums of daily averages.

2 Daily averages. 
puparia, of which they made use for purposes of oviposition, whereas those having access to but one or two host puparia, especially those of the smaller host, Musca domestica, produced the least progeny. These experiments were performed at various times in the laboratory and are by no means conclusive, that is, do not establish the range or average of fecundity.

Table III. Progeny of Single Females of Nasonia brevicornis.

\begin{tabular}{|c|c|c|c|c|c|c|c|c|c|c|}
\hline \multirow{2}{*}{$\begin{array}{c}\text { Female } \\
\text { No. }\end{array}$} & \multirow{2}{*}{$\begin{array}{l}\text { Date, } \\
1908 .\end{array}$} & \multirow{2}{*}{ Host. } & \multirow{2}{*}{$\begin{array}{l}\text { No. of } \\
\text { hosts } \\
\text { ex- } \\
\text { posed. }\end{array}$} & \multirow{2}{*}{$\begin{array}{c}\text { No. of } \\
\text { hosts } \\
\text { infested. }\end{array}$} & \multicolumn{3}{|c|}{$\begin{array}{l}\text { Progeny of single } \\
\text { females. }\end{array}$} & \multirow{2}{*}{ 离 } & \multirow{2}{*}{ 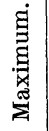 } & \multirow{2}{*}{ 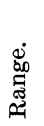 } \\
\hline & & & & & o's. & Q's. & Total. & & & \\
\hline 1 & Sept. 25 & Musca & 1 & 1 & 1 & 6 & 7 & & & \\
\hline 2 & & & 1 & 1 & 4 & 6 & 10 & & & \\
\hline 3 & & & 1 & 1 & 5 & 6 & 11 & & & \\
\hline 4 & & Phormia & 1 & 1 & & & 27 & & & \\
\hline 5 & & & 2 & 2 & & & $38+1$ & & & \\
\hline 6 & & & 4 & 4 & & & 39 & & & \\
\hline 7 & Sept. 28 & Musca & 4 & 4 & 2 & 17 & 19 & & & \\
\hline 8 & & & 1 & 1 & 1 & 2 & 3 & 3 & & \\
\hline 9 & Sept. 30 & & 1 & 1 & 2 & 4 & 6 & & & \\
\hline 10 & Oct. & Phormia & 5 & 4 & 9 & 18 & 27 & & & \\
\hline 11 & Oct. 1 & & 1 & 1 & 2 & 8 & 10 & & & \\
\hline 12 & Oct. 20 & & Many & 一 & 7 & 12 & 19 & & & \\
\hline 13 & & & Many & 一 & 4 & 22 & 26 & & & \\
\hline 14 & & & 130 & 17 & 21 & 57 & 78 & & & \\
\hline 15 & & & 86 & 22 & 38 & 65 & 103 & & 103 & 100 \\
\hline 16 & & Chrysomyia & 17 & 12 & 31 & 53 & 84 & & & \\
\hline
\end{tabular}

It is thus seen that in one instance, a female was able to parasitize successfully 22 host puparia and another 17 , when quite a number were available. The observations do no more than indicate the probabilities and possibilities of fecundity for the species. Apparently, all of the females concerned were fertilized. From the fact that single ovipositions take so much time, as well as for other reasons, we strongly suspect polyembryony in this connection.

H. Proportion of the Sexes. The following results, recorded in table IV, comprise actual counts of over seven thousand specimens, including practically every individual of this parasite reared or observed by us during the period of breeding, excepting one thousand individuals of mixed sexes released for experimental purposes.

1 All from one of the puparia; the numerous larvae in the other died and were not counted. 
The specimens are from various sources, but the great majority were reared from puparia obtained under natural conditions, so that the general result should show a nearly normal or actual ratio of the sexes. The table follows.

Table IV. Proportion of the Sexes in Nasonia brevicornis.

\begin{tabular}{|c|c|c|c|c|c|c|c|}
\hline $\begin{array}{l}\text { Lot } \\
\text { No. }\end{array}$ & Source. & $\begin{array}{l}\text { Date. } \\
1908 .\end{array}$ & Males. & Females. & Total. & Ratio. & Remarks. \\
\hline 1 & $\begin{array}{l}\text { Principal } \\
\text { misc. rearings } \\
\text { during season }\end{array}$ & Sept. 9-Oct. 20 & 142 & 438 & 580 & $1: 3$ & $\begin{array}{l}\text { Comprises all ac- } \\
\text { cessioned rear- } \\
\text { ings. See pp. } \\
7-9 .\end{array}$ \\
\hline 2 & $\begin{array}{l}\text { Nason Collec- } \\
\text { tion }\end{array}$ & $\begin{array}{c}\text { May 11-Sept. } 17 \\
1894-1895\end{array}$ & 1 & 9 & 10 & $1: 9$ & $\begin{array}{l}\text { From sweepings, } \\
\text { Algonquin, Illi- } \\
\text { nois. }\end{array}$ \\
\hline 3 & $\begin{array}{l}\text { Phormia regi- } \\
\text { na }\end{array}$ & Sept. 29 & 710 & 786 & 1496 & $1: 1+$ & $\begin{array}{l}\text { From a single host } \\
\text { lot from a de- } \\
\text { composed cad- } \\
\text { aver, city dump- } \\
\text { ing-grounds. }\end{array}$ \\
\hline 4 & $\begin{array}{l}\text { Phormia regi- } \\
\text { na }\end{array}$ & Oct. & 1895 & 2808 & 4703 & $1: 1+$ & $\begin{array}{l}\text { Same as lot No. } 3 \text {, } \\
\text { later, excluding } \\
1000 \text { removed at } \\
\text { random for ex- } \\
\text { perimental pur- } \\
\text { poses. }\end{array}$ \\
\hline 5 & $\begin{array}{l}\text { Phormia regi- } \\
\text { na }\end{array}$ & Oct. & 228 & 116 & 344 & $2: 1+$ & $\begin{array}{l}\text { Host puparia in } \\
\text { fecal matter, } \\
\text { miscellaneous. }\end{array}$ \\
\hline 6 & Various & Sept. & 41 & 49 & 90 & $1: 1+$ & Reared. \\
\hline 7 & Various & Sept.-Oct. & 64 & 82 & 146 & $1: 1+$ & $\begin{array}{l}\text { From isolated pu- } \\
\text { paria of Musca, } \\
\text { Sarcophaga, } \\
\text { Phormia and } \\
\text { Chrysomyia. }\end{array}$ \\
\hline Sums: & & & 3081 & 4288 & 7369 & $1: 1+$ & \\
\hline $\begin{array}{l}\text { Per- } \\
\text { cent.: }\end{array}$ & & & $41.81 \%$ & $58.19 \%$ & & & \\
\hline
\end{tabular}

The general result shown in the table is about what one would expect if consideration is taken of the fact previously pointed out, namely, that the species is occasionally parthenogenetic, which, however, follows no general law in the Hymenoptera. It should be explained, in regard to lot No. 4 in the table that, after it was separated from lot No. 3, the first 1000 individuals of mixed sexes coming to 
the light were removed and released to be used in an experiment to test artificial propagation. Unfortunately, these were not counted in regard to sex, so that it is unknown whether the females greatly predominated, a result which we were led to suspect from the fact that this sex appeared to be more attracted to light; for the first 932 individuals taken from the experiment, after all emergences, were females, dead in the exit-tube, which alone was light. Lot No. 3 is the most complete record made, none of the emerging parasites having escaped, and we are inclined to think that it represents the actual ratio of the sexes, the females slightly predominating.

The proportion of the sexes in a small number of the parasites which hibernated as larvae, hence the parents of the first spring generation, was as 37 males are to 61 females; these emerged during the last day of April, 1909. Their descendents or parents of the $2 \mathrm{~d}$ generation were also of mixed sexes, being the progeny of fertilized females, there being 24 males to 45 females, which emerged on May 25, 1909.

I. Emergence of the Adult. In general, it may be stated that the adult parasites emerge from the host puparium through from 1 to 3 circular holes, situated variously, usually in the dorsal or dorso-lateral aspect; and when more than one exit-hole, the two or three are usually scattered or widely separated. The manner of emergence does not differ for sex. The exit-hole varies in diameter from about 0.75 to $1.50 \mathrm{~mm}$.; it is usually larger and single when the host is Musca or Chrysomyia and smaller when Phormia, though this difference may be more apparent than real. Individual exit-holes may of course vary considerably in shape; for rarely it may involve the whole of one end of the host puparium and is then relatively very large and irregular. The margins of the exit-holes are always jagged or serrate, showing that the adults gnaw their way out. Specific instances may better illustrate.

From a single puparium of Musca domestica, 1 male and 6 females issued from a single dorsal exit-hole just behind the head end; several parasites of both sexes issued from another puparium from a hole in the dorsal aspect of the 7th segment; several adults of both sexes issued from a third puparium through two exit-holes in the cephalic and caudal segments respectively. Again, 1 male and 2 females emerged from a more irregular exit-hole in the dorso-lateral aspect of the caudal or anal segment of the host. In a last case recorded, $2 \sigma^{\top} \sigma^{\top}$ and 4 우 우 issued from a single hole near the cephalic end of the host. 
In the case of Phormia regina. From one puparium, 7 females issued from a single hole in the lateral aspect of the 3rd segment; from a second, 37 males issued from 2 holes in the ventro-lateral aspect of segments 2 and 5 ; from a third 15 males issued from a single hole in the dorso-lateral aspect of segment 5 ; from four more puparia, of the same lot, 9 males and 18 females issued, making but a single exit-hole in each of the hosts. In each of the following instances several parasites issued in the manner stated; both sexes were present:

(a.) 2 similar holes in a longitudinal line, dorsal aspect of $2 \mathrm{~d}$ and 4 th segments. (b.) 3 holes, lateral aspect, 2 on one side at segments 3 and 7, the other at segment 2 on the opposite side. (c.) 2 holes, lateral aspect of segment 5 and tip of the anal segment. (d.) 2 holes, dorsal aspect of segment 3 and dorso-lateral aspect of the anal segment. (e.) 2 holes in an oblique line, dorsal aspect, 5th and 7th segments. (f.) 1 hole, lateral aspect of segment 3. (g.) 1 hole lateral aspect of segment 6 . (h.) 2 holes, opposite sides, lateral aspect of penultimate segment and dorso-lateral aspect of segment 7. (i.) 3 holes, scattered. (j.) 2 holes. (k.) 2 holes caudal end, dorsal and ventral aspects of the penultimate segment.

With Chrysomyia, several adults issued from a single puparium through a single hole in the dorso-lateral aspect of the cephalic segment; from 12 puparia of this species, there emerged 32 males and 64 females, or an average of 8 to each; in the case of 8 of the puparia, but a single exit-hole was present, nearly all in the dorsal aspect of the $3 \mathrm{~d}, 4$ th, 5th and 8th segments; the remaining 4 hosts bore each 2 exit-holes, usually widely separated.

In Cynomyia cadaverina Desv., $8 \sigma^{\nwarrow} \sigma^{\top}, 16$ 우 우 issued from a single puparium from two equal round holes in the dorso-lateral aspect of segments 3 and 5 .

In regard to the time of emergence, the males usually emerge from 2 to 20 hours earlier than the females, a few emerging some hours previous to the simultaneous emergence of the majority, but there is considerable variation in individual cases. Thus some males may be the last to emerge, but the tendency is for them to emerge earlier than females.

J. Local Abundance. In order to show the local abundance of this parasite during 1908, we have merely to point out the fact that as many as eight thousand or more specimens were reared by us during the months of September and October. This large number 
was reared quite incidentally, that is to say, without conscious effort on our part to augment it. From one experiment alone, there were obtained as many as seven thousand specimens, in round numbers, though we have no knowledge concerning the number which may have escaped. Further, the local abundance of this parasite is indicated by the fact that in at least a portion of the experiment just mentioned, a portion selected at random, the percentage of parasitism was as high as 90 per cent. We have evidence to show, on the other hand, that this percentage of mortality of the host was by no means general but was considerably lower on the average for this season of the year.

Thus, apparently this parasite had concentrated its attack at certain spots and while common over this locality was not exceedingly abundant over the whole, as the percentage of mortality given in the instance just mentioned would seem to indicate.

It was the most abundant parasite present in our experiments and also the one which attacked the greatest numbers of different muscid hosts, the remaining chalcidoid parasites of importance mainly confining themselves to the house fly.

K. Artificial Propagation. An unsuccessful attempt was made during the last week of September, 1908, to test the effect of the artificial propagation of this parasite on a badly infested garbage heap at the city dumping-grounds, Champaign, Illinois. The attempt was made too late in the season, however, and in addition, bad weather immediately following their liberation undoubtedly prevented activity on their part.

On the afternoon of September 23, 1000 specimens of mixed sexes were scattered over the garbage heap, which at that time was a veritable breeding experiment on a large scale. Soon after their liberation, many of the parasites were noticed crawling over host puparia which had been formed about a half-inch below the surface of the soil along the edges of the garbage heap. Specimens other than those liberated were not noticed at the time, special search being made for them previous to liberation.

On the date the experiment was inaugurated the percentage of parasitism by this species was very low as we know from the results obtained from a collection at random of 186 puparia; for by November $6,1908,48$ adult flies had emerged (of which 37 were Musca domestica), 6 Spalangia and 2 Muscidifurax raptor Girault and Sanders MS. An examination made of the remaining 130 hosts, which were hibernat- 
ing in confinement as puparia, revealed the fact that the majority had died and that no further parasitism had occurred. After inauguration of the experiment, weekly collections of the host puparia were made from the heap of garbage and continued until the first week of November. The lot collected on September 30 had one puparium infested with brevicornis but from these collected thereafter no results were obtained, the collections unfortunately being placed in the warm insectary and subsequently neglected. Nor were any adults of the parasite seen during the visits to the heap in the late fall and early winter. From a lot of hosts collected on November 14, however, the garbage then being covered with snow, sometime during late November single females of brevicornis issued from a puparium of Chrysomyia macellaria and from one of Phormia regina; these were evidently greatly accelerated in development by the warmth of the insectary and would otherwise have hibernated within the puparia of the hosts. The remaining lots were examined early in the spring of 1909, but everything was dead and no indications of parasitism were found.

L. Hibernation. This parasite hibernates as a full-grown larva in the puparia of its various hosts, pupating early in the spring and emerging shortly afterwards, the earliest record being April 28, 1909 in numbers the following day. The following data have been gathered concerning this phase in its life-cycle.

Case I. On April 28, 1909, a single broken puparium of Chrysomyia macellaria was found in a vial in the cold insectary which had evidently been laid aside late in the previous October and subsequently overlooked. The vial had no data connected with it, so that the origin of the single host could not be traced. With the broken puparium were found a living male adult, partly excluded from the pupal integument and four healthy pupae of the parasite, two of which were uniformly deep black, showing the nearness of the final ecdysis; the other two were creamy white in color. The five meconia appeared to be freshly deposited. On the following day, by 9: $30 \mathrm{~A}$. M., a female had emerged and shortly afterwards (9: 52) was observed mating with the male; at 10: $30 \mathrm{~A}$. M., another female emerged. The two remaining pupae died.

Case II. A puparium of Phormia regina (Meigen) taken from refuse matter was inclosed in a vial on October 1, after having been carefully broken open in order to ascertain the presence of parasites; six apparently full-grown larvae of the parasite were found within. 
On Oct. 28, 1908, it was noted that the larvae remained unchanged; no further note was made until April 28, 1909, when four fully colored pupae and one white one, were found, as well as five meconia, the shriveled remains of a larva of the parasite and the remains of the host pupa. At 10 A. M., April 29, 1 male and 2 females were found recently emerged; by the following day, at the same hour, another female had emerged. The remaining pupa died. All were in natural temperatures.

Case III. In a vial containing 20 puparia and 20 dead larvae of Phormia regina - including a single puparium of Chrysomyia macellaria - which were obtained from refuse matter late in October, 1908, and thus confined, there were found on April 28, 1909, 11 of the puparia infested with the parasite as follows. All were in natural temperatures.

\begin{tabular}{|c|c|c|c|c|c|c|}
\hline No. & Host. & Larvae. & White pupae. & Black pupae. & Adults. & Total. \\
\hline 1. & Phormia & 2 dead +1 . & 3. & 3. & & 9. \\
\hline 2. & (broken). & & & 1. & & 1. \\
\hline 3. & & & 2 . & 4. & & 6. \\
\hline 4. & & & & 9 . & $1 \sigma^{\nearrow}, 1$ 우. & 11. \\
\hline 5 . & & & & 8. & & 8. \\
\hline 6 . & & & 1. & 5 . & & 6. \\
\hline 7. & & & & 6. & & 6. \\
\hline 8. & & & & 7. & & 7. \\
\hline 9. & & 1. & & 10 . & & 11. \\
\hline 10 . & & 1 dead. & 6 . & 8. & & 15. \\
\hline 11. & $\begin{array}{l}\text { Chrysom- } \\
\text { yia. }\end{array}$ & & & 5. & $1 \sigma^{x}$ & 6. \\
\hline
\end{tabular}

In addition, lying loose in the vial were found 6 dark pupae and 1 recently formed, as well as one adult regina. Thus the parasite was found in three stages - nearly all of the larvae had pupated and the adults were just beginning to emerge. On the following day, emergence became general throughout the whole lot and was completed on May 3d, some of the younger white pupae dying. Of the total number of parasites in this case there were more females than males.

The sixty-one larvae recorded in table I, of which 38 were alive and healthy, were evidently hibernating, as the puparia had been in confinement for over a month, and those parasites which matured had long since emerged. A few Phormia puparia, infested and isplated on Sept. 15, 1908, contained living, full-grown larvae on Nov. 7, 1908. 
M. Courting and Mating. Courting in this insect is not a complex habit. It follows almost immediately after emergence, at least in confinement. Where a number of both sexes are gathered together, all recently emerged, the males and females are constantly in motion, the former active, seeking the females, the antennae of both sexes also constantly in motion, held inclined upward in the natural position, giving quick, jerky, wavy movements. When one individual meets another, the antennae simply touch whichever portion of the body presents itself first and the two turn aside and pass on; or if they happen to be individuals of opposite sex and (apparently) the occasion is suitable - which is most often the case immediately following emergence - the male hastily climbs upon the back of the female, runs forward, and grasps her head with the fore feet, usually at the lateral aspect of the eyes or sometimes at the cheeks; the intermediate feet grasp some portion of the thoracic pleura, usually at the mesothorax and the hind feet take hold along the sides of the abdomen or the edges of the flat wings. The legs are not stretched out or used for embracing the body of the female but the hold is taken by the feet alone, and the position of the male is not strained but rather that of the natural position of rest. His body is parallel with and above the body of the female and projects beyond (cephalad) it, so that the head is between the upturned antennae of the female and stretched over hers, his abdomen reaching to a point above the third abdominal segment or to a point opposite to the distal end of the marginal vein of the fore wings upon which it actually rests. Having quickly attained this position, the male senses the antennae of the female with his own and immediately begins suit in earnest by rubbing his head up and down against the inner (mesal) surfaces of the flagella of the female,- which are held upward in a V-shaped position,- at the same time holding the scapes erect and apart and the flagella back, pointing laterad at rightangles to the scape and at every downward movement bringing the scapes together; this movement of the head is accompanied by a corresponding "petting" movement of the female flagella against the cheeks of the male. The up- and downward movements of the head are regular and continued for from 5 to 10 seconds, each completed movement occupying slightly less than a second of time; and they are alternated with a period during which the head of the male is motionless and his antennae sensing those of his mate, either by touching both of their tips to the tips of her antennae, or else by stroking 
them up and down, the mandibles, maxillae and labium with both pairs of palpi are themselves in almost constant motion, but so far as observed, they play no part as organs of sensation, with the possible exception of the maxillary palpi. Sometimes, the male rubs but one of the flagella of the female, turning the head to one side. No other movements than these are observable, but there is some variation in the occurrence of either of the two movements described, and also in the number of times they are repeated before sexual union is permitted by the female. The male may be received coldly; he may make the movements without attempting union, or after alternating them three or four times, he may attempt union without success and then run forward to repeat the actions, and this may continue as long as the female permits, either resulting successfully or unsuccessfully. In the presence of other females, if received coldly, the male soon tires, leaves and seeks another mate. In order to attempt union, the male has to reverse his position, and run back to the tip of the abdomen of the female where he usually reaches over the tips of the wings and senses with the antennae, quickly turning and reaching around again with the tip of his abdomen, to gain entrance into the vaginal orifice. Or, on the other hand, he may simply back quickly to the caudal end of the female and attempt union. In one case, previously cited. coition lasted for fourteen seconds; in another, for ten seconds. Mating is promiscuous for both sexes.

The following example may be cited. From a puparium of a host a male emerged during the afternoon of April 28, 1909; by 9:30 A. M. the following day a female had emerged, and shortly afterwards the pair were in ardent courtship; at 9:45 A. M., sexual union occurred, lasting for ten seconds. The male then ran forward again over the back of his mate and rubbed his head up and down her flagella, one of the movements of courtship; he then left. After 30 seconds the male again quickly mounted his mate and repeated the two alternate movements, described in foregoing, continuously for 45 seconds and left for the same length of time. After a minute of attentions he made an unsuccessful attempt to unite with the female, and then left her for some time (12 minutes). Courting was recommenced after this interval of time, continuing for five minutes but with no attempt to unite. Subsequent matings followed during the next 24 hours, though 13 minutes after the last visit of the male, the female had crawled to some host puparia which engaged her attention, and both were less taken with each other. 
N. Effective Parasitism.

What may be included under this term is an interesting phenomenon in those relations which a parasite sustains to its host. Under natural conditions it may never occur, and here it was observed accidentally. Whether or not a parasite can overcome the effects of development in a host at the time just preceding an ecdysis, when development is liable to be very rapid, is not a very important question, excepting when it is concerned with a host stage of very short duration such as is not present here. Nasonia, so far as we know, confines its attacks exclusively to the puparia of its various hosts; this stage is usually of short duration, but not exceptionally short as is the egg stage, so that the period of rapid development immediately preceding the final ecdysis, being short, would not materially prolong the period open to parasitism - that is, the pupal stage - if it in turn were likewise open. The following cases are, therefore, of interest mostly from the scientific standpoint. The host was Cynomyia cadaverina in the stage just preceding the final eclosion, though this fact was unknown when the hosts were exposed to the parasites in confinement in order to insure a second generation. The parasites were those from hibernated larvae, or parents of the first generation. The host puparia were formed on April 23, and were thus six or more days old.

Case I. Three virgin females of the parasite emerging at 1:30 P. M., April 29, 1909, were at once confined separately in vials, each with four of the host puparia. Oviposition was not observed. The hosts were then six days old; by 9 A. M., May 1, eight of the host puparia had excluded adults which were at once released; another adult excluded at 11:20 A. M., May 1st, and two more at 8:30 A. M., May $2 \mathrm{~d}$; the single remaining puparium was apparently successfully parasitized by one of the females but upon examination on May 15, 1909, no traces of parasites could be found.

Case II. A pair of adults of the parasite which had mated for the first time at 9:45 A. M., April 29, were confined in a vial with eight of the host puparia; the female noticed the hosts at once but left them and was engaged with the male for a short while. During the afternoon, however, she commenced to deposit eggs; at 10:08 P. M., April 30, a host fly emerged and again at 10:25 P. M., the same day, when the mother parasite was engaged in depositing into another host. At 9 A. M., and 7 and 9 P. M., May 1, three host flies emerged, and again on May 2, at 11 A. M., and 5 P. M. The remaining host was 
successfully parasitized, it having been partly opened at 3 P. M., May 13 and found to contain larval parasites. In this case the parasite was successful up to within about 24 hours of the final ecdysis, the host pupa being perfect and with all the colors of the mature adult.

Case III. At 11:20 A. M., April 29, nine males and twenty females of the parasite, which had been freely mating, were confined together under a bell-jar with ten of the host puparia; oviposition was observed at noon and was continued with persistence until noon, May 3, when the observations had to be discontinued. During this time none of the hosts emerged, though in a control lot, emergence became general early on May 1, beginning during the morning of April 30. Hence in this case, the parasites being in greater numbers, not a single host escaped.

Summarizing, parasitism by Nasonia is "effective" or successful in many cases almost up to within the few hours immediately preceding the final ecdysis, depending on circumstances; a single female parasite, for example, would be able to kill a single host puparium up to within about 15 hours of eclosion, but where a number were present, many would escape before she would be able to deposit into them. And the converse is true. The host when thus attacked is a perfect pupa and fully colored.

O. Length of Life in Confinement; Adults.

The adults of this parasite lived for about five days on the average in confinement, the males dying somewhat earlier. They were unfed in all cases.

P. Change in Coloration of the Pupa. When first formed the pupae are yellowish white, the eyes garnet, with some duskiness at the caudal edges of the abdominal segments soon afterwards; the mandibles, legs, antennae and wing-pads gradually become dusky and about 48 hours previous to eclosion, the head, thorax and abdomen, in succession, begin to show dark color, the head and thorax together becoming a deep black before the abdomen shows very much color, and then after about 6 hours, the latter turns gradually but rapidly black. About 20 hours before eclosion, the color is jet black, which just preceding emergence changes nearly to the colors of the mature adult. At eclosion, the adults are fully colored. 


\title{
LITERATURE REFERRED TO.
}

1878. Thomson, C. G. Hymenoptera Scandinaviae, Lundae, V, pl., fig. 18. 1896. Ashmead, William H., Descriptions of new Parasitic Hymenoptera. Trans. American Ent. Soc., XXIII, p. 221.

1904. Ashmead, William H., Classification of the Chalcid flies or the Superfamily Chalcidoidea. Mem. Carnegie Mus., Pittsburgh, I. (Publications of the Carnegie Museum, Serial No. 21.) pp. xi, 317-318.

1906. Nason, William A., Parasitic Hymenoptera of Algonquin, Illinois.IV. Entomological News, Philadelphia, May, XVII, p. 221.

The Harris Memorial Tablet.

On Friday, December 31, the final day of the recent entomological meetings in Boston, delegates from the various Societies represented in those meetings went out to Milton village, and with brief ceremony unveiled a simple marble tablet placed on the old "Suffolk Resolves mansion" to commemorate the residence there of Thaddeus William Harris. ${ }^{1}$

The inscription, composed by Colonel Thomas Wentworth Higginson, who in his student days was a pupil of Harris, reads as follows:

\author{
IN THIS HOUSE FROM 1824 TO 1831 DWELT \\ THADDEUS WILLIAM HARRIS M. D. \\ BOTANIST, ENTOMOLOGIST; AND FINALLY \\ LIBRARIAN OF HARVARD COLLEGE \\ IN EACH CAPACITY HE WON \\ FOR HIMSELF FAME AND GRATITUDE \\ HE HAD THE MODESTY AND UNSELFISHNESS \\ OF TRUE SCIENCE \\ WITH WHAT MAY RIGHTLY BE CALLED \\ ITS CHIVALRY OF SPIRIT
}

Besides the entomologists, there were present representatives of the Milton Historical Society and the Science Club of Milton Academy.

W. L. W. FieLd. 

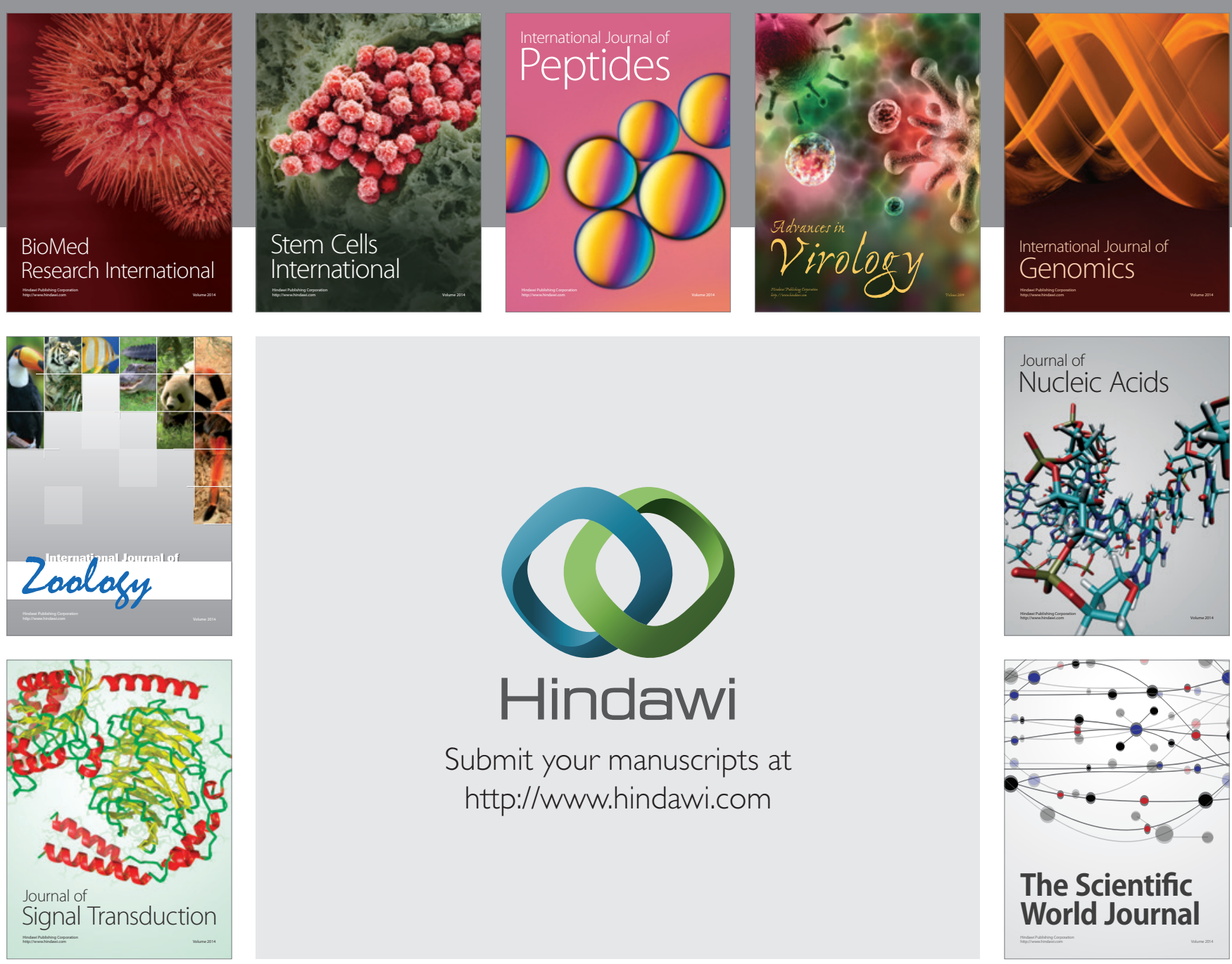

Submit your manuscripts at

http://www.hindawi.com
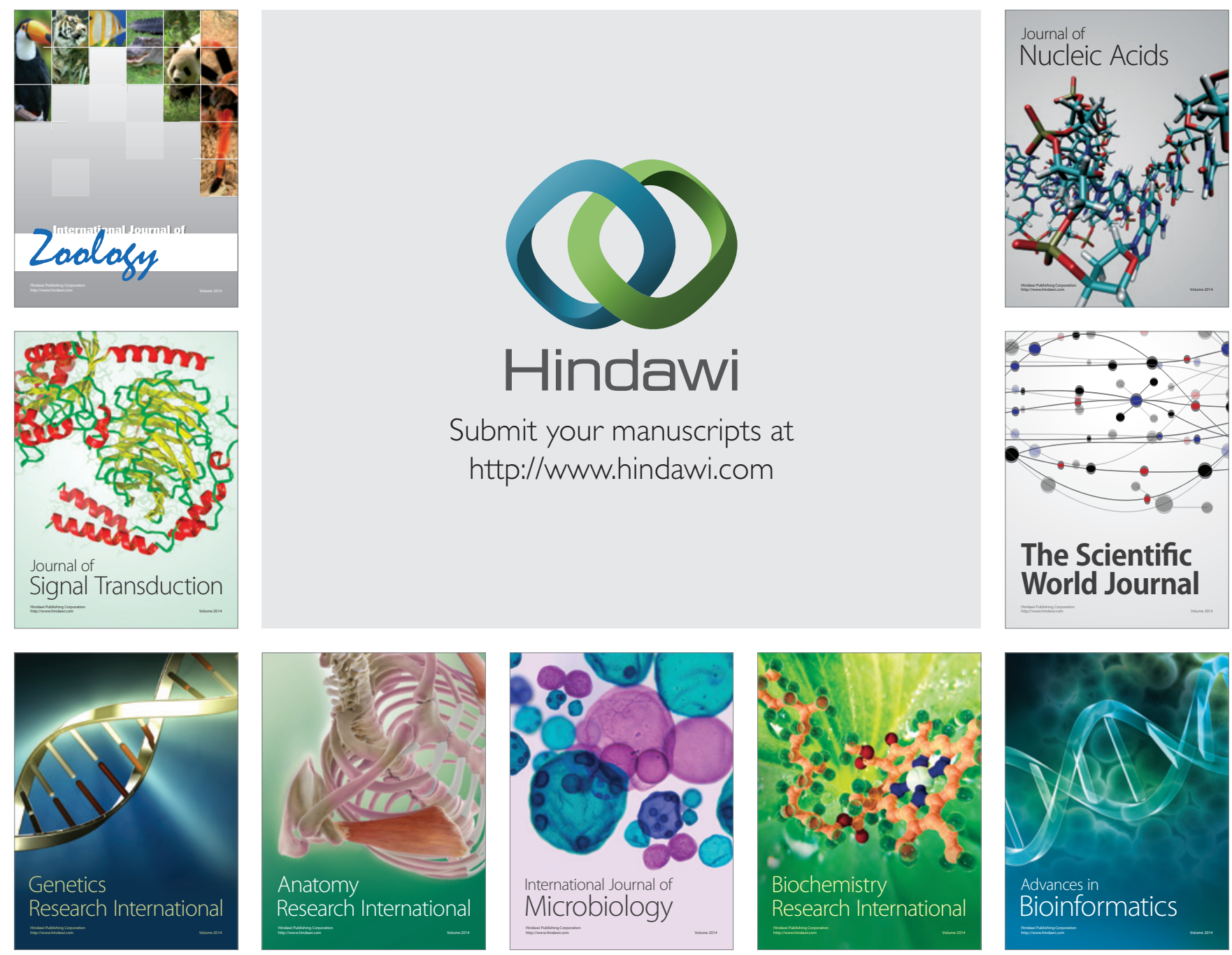

The Scientific World Journal
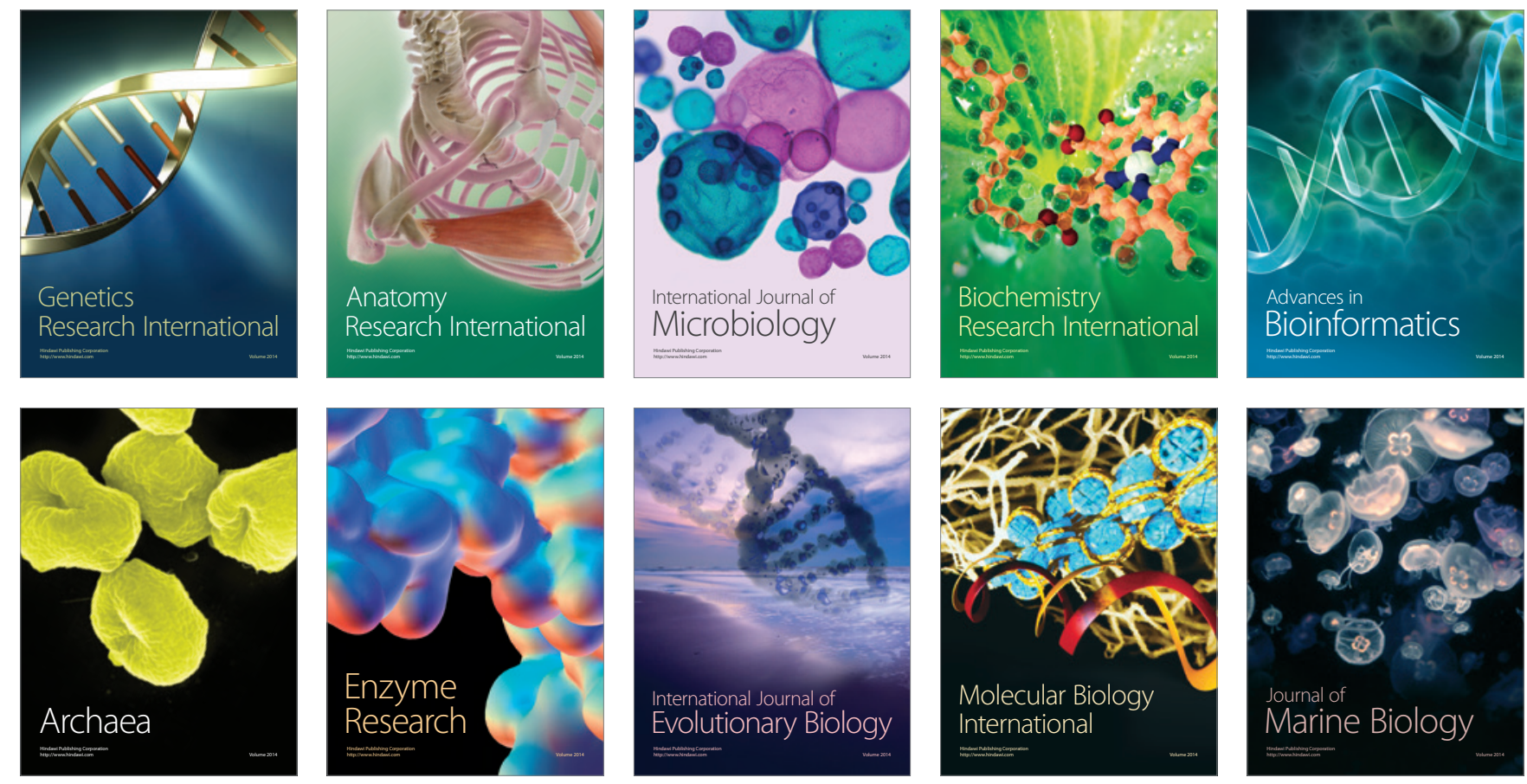